\title{
Lung Mucinous Cystadenoma
}

National Cancer Institute

\section{Source}

National Cancer Institute. Lung Mucinous Cystadenoma. NCI Thesaurus. Code C45604.

A very rare, well circumscribed, benign cystic neoplasm that arises from the lung. It is characterized by the presence of cysts which are lined by tall mucinous epithelium and filled with mucin. 